\title{
A Disrupted-in-Schizophrenia 1 Gene Variant is Associated with Clinical Symptomatology in Patients with First-Episode Psychosis
}

\author{
Javier Vázquez-Bourgon ${ }^{1,2} \bowtie$, Ignacio Mata ${ }^{2}$, Roberto Roiz-Santiáñez ${ }^{1,2}$, Rosa Ayesa-Arriola ${ }^{1,2}$, \\ Paula Suárez Pinilla1, Diana Tordesillas-Gutiérrez ${ }^{1,2}$, José Luis Vázquez-Barquero ${ }^{1,2}$, and \\ Benedicto Crespo-Facorro ${ }^{1,2}$
}

1'Department of Psychiatry, University Hospital Marqués de Valdecilla-IFIMAV, School of Medicine, University of Cantabria, Santander, Spain ${ }^{2}$ Centro de Investigacion Biomedica en Red de Salud Mental (CIBERSAM), Madrid, Spain

Objective DISC1 gene is one of the main candidate genes for schizophrenia since it has been associated to the illness in several populations. Moreover, variations in several DISC1 polymorphisms, and in particular Ser704Cys SNP, have been associated in schizophrenic patients to structural and functional modifications in two brain areas (pre-frontal cortex and hippocampus) that play a central role in the genesis of psychotic symptoms. This study tested the association between Ser704Cys DISC1 polymorphism and the clinical onset of psychosis.

Methods Two hundred and thirteen Caucasian drug-naïve patients experiencing a first episode of non-affective psychosis were genotyped for rs821616 (Ser704Cys) SNP of the DISC1 gene. The clinical severity of the illness was assessed using SAPS and SANS scales. Other clinical and socio-demographic variables were recorded to rule out possible confounding effects.

Results Patients homozygous for the Ser allele of the Ser704Cys DISC1 SNP had significantly ( $<<0.05)$ higher rates at the positive symptoms dimension (SAPS-SANS scales) and hallucinations item, compared to Cys carriers.

Conclusion DISC1 gene variations may modulate the clinical severity of the psychosis at the onset of the disorder.

Psychiatry Investig 2014;11(2):186-191

Key Words DISC1 ser704cys, Genetics, Hallucinations, Schizophrenia, Severity of illness.

\section{INTRODUCTION}

Disrupted-in-Schizophrenia 1 (DISC1) and DISC2 genes are located at the breakpoint of a chromosomal translocation at $1 \mathrm{q} 42.1(1 ; 11)$ (q42.1;q14.3), which was firstly described to be linked to major psychiatric disorders, including schizophrenia, in a Scottish family. ${ }^{1}$ Subsequent studies on different ethnic populations provided further evidence supporting the role of DISC1 as a susceptibility gene for Schizophrenia spectrum disorders. ${ }^{2-12}$

The biological functions of DISC1 are not completely un-

Received: April 19, 2013 Revised: June 28, 2013

Accepted: July 15, 2013 Available online: April 11, 2014

$\triangle$ Correspondence: Javier Vázquez-Bourgon, MD

Department of Psychiatry, University Hospital Marqués de Valdecilla-IFI-

MAV, School of Medicine, University of Cantabria, Avda. Valdecilla s/n, 39008

Santander, Spain

Tel: +34-942-202537, Fax: +34-942-203447, E-mail: javazquez@humv.es

(a) This is an Open Access article distributed under the terms of the Creative Commons Attribution Non-Commercial License (http://creativecommons.org/licenses/by$\mathrm{nc} / 3.0$ ) which permits unrestricted non-commercial use, distribution, and reproduction in any medium, provided the original work is properly cited. derstood, and still there is no clear knowledge on how variations in DISC1 gene could increase the risk of schizophrenia. However there is growing evidence regarding the involvement of DISC1 protein in neurodevelopmental processes and neural cell signalling through its interaction with the binding protein complex known as DISC1 interactome; being FEZ1, NEDL1, PDE4, or PSD95 among the proteins included in this complex. ${ }^{13,14}$

During the last decade, the study of the relation between DISC1 and different schizophrenia endophenotypes (e.g., brain structure and function, cognitive abnormalities), has provided evidence of association between variations in several DISC1 polymorphisms and brain structure, altered brain function and impaired cognitive performance, both in schizophrenic patients and in healthy subjects. ${ }^{4,5,15-22}$ However, few studies have examined the relationship between this gene and the clinical presentation in schizophrenia. ${ }^{11,23-25}$ These studies have reported associations between different DISC1 polymorphisms and positive psychotic symptoms -hallucinations 
and delusions-, ${ }^{24,25}$ as well as psychosis-related traits both in schizophrenic patients and in healthy individuals. ${ }^{11,23}$ However none of these studies have examined a sample of first-episode patients, thus allowing to control the confusion effects derived from the treatment and chronicity of the illness.

Among all the numerous DISC1 polymorphisms which have been described, the Ser704Cys (rs821616) appears to be especially relevant as it has been previously related to different aspects of schizophrenia. Specifically, variations in this particular polymorphism have been associated not only to the risk of having schizophrenia, ${ }^{7}$ but also to several endophenotypes, such as brain structural and functional abnormalities, ${ }^{7,15,18}$ cognitive impairment, ${ }^{7,17,20}$ and even clinical presentation. ${ }^{23,25}$ All these studies have found that carriers of the Ser allele (or Ser/Ser genotype) have an increased risk for showing a higher severity of the different abnormalities mentioned above.

The aim of the present study was to examine, in a well-characterized and representative series of patients experiencing a first episode of a non-affective psychosis, whether an association between DISC1 Ser704Cys polymorphism and clinical presentation exists. We hypothesized that carriers of the Ser allele (or Ser/Ser genotype) will show a more deleterious illness onset, with an earlier age of onset and higher psychopathological severity.

\section{METHODS}

The sample for the present study consisted in 213 unrelated Caucasian subjects of Spanish origin. The subjects formed part of a large prospective longitudinal study on first episode non-affective psychosis (PAFIP) ${ }^{26}$ Those patients referred to the program presenting a first episode of non-affective psychosis were admitted to the programme if fulfilling the following criteria: 1.-aged 15-60; 2.-meeting DSM-IV criteria (by means of the Structured Clinical Interview for DSM-IV, SCIDI) 6 months after inclusion for a principal diagnosis of, schizophrenia, schizophreniform disorder, schizoaffective disorder, brief reactive psychosis, delusional disorder, or psychosis non otherwise specified; 3.-habitually living in the catchment area; 4.-no prior treatment with antipsychotic medication; and 5.-current psychotic symptoms of at least moderate severity, as assessed by one of the five items of the Scale for the Assessment of Positive Symptoms (SAPS). Patients were not admitted to the programme if presenting any of the following: 1.-mental retardation; 2.-neurological disorder; or 3.-drug dependence (DSM-IV criteria).

Clinical assessments were carried out with the Scale for the Assessment of Positive Symptoms (SAPS), ${ }^{27}$ Scale for the Assessment of Negative Symptoms (SANS), ${ }^{28}$ and the Clinical Global Impression-Severity scale (CGI-S), by a senior psychi- atrist (BC-F), who was blind to genotype. The positive, negative and disorganized symptom dimensions were calculated from SAPS and SANS scales, ${ }^{29,30}$ and were used to measure the clinical severity of the illness. The positive symptom dimension is the sum of global scores for the SAPS items hallucinations and delusions. The negative symptom dimension is the sum of global scores of the following SANS items: alogia, affective flattening, avolition-apathy, and anhedonia-asociality. And the disorganized symptom dimension is the sum of the items: positive formal though disorder, disorganized/bizarre behaviour, and inappropriate affect.

All subjects gave written informed consent prior to their inclusion in the study, which was approved by the local ethics committee (University Hospital Marques de Valdecilla Ethics Committee).

The control group, which consisted in 303 subjects, was obtained from the Blood Bank of the University Hospital Marques de Valdecilla. All subjects in the control group gave consent for their blood to be genotyped for research purposes.

Genomic DNA was extracted from peripheral white blood cells obtained from each subject according to standard protocols. The Ser704Cys DISC1 polymorphism-rs821616-was genotyped using SNPlex technology (Applied Biosystems, Foster City, CA, USA).

All statistical analyses were carried out using the statistical software package SPSS 15.0 for Windows. For the analysis of categorical variables, Chi square analyses were carried out. For the analyses of the relation between Ser704Cys genotype and continuous variables, we used analysis of variance (ANOVA) tests. Statistical significance was established at $\mathrm{p}<0.05$.

After completing the association analysis by genotype, and in order to facilitate comparison to previous studies, we conducted exploratory analysis of association clustering the patients into two groups according to being homozygous for the Ser allele or carrying the Cys allele.

\section{RESULTS}

Gender distribution was 123 males (57.7\%) and 90 females (42.3\%). Mean age of onset in our sample was 27.3 years ( $\mathrm{SD}=$ 7.8), higher than what has commonly been reported. The mean duration of untreated psychosis (DUP) at initial assessment was 14.5 months ( $\mathrm{SD}=29.4$, median $=4)$.

Among the control group, 177 (59.8\%) were male, and 126 (41.6\%) were female. Due to the origin of the control sample, sex was the only socio-demographic variable available for the current study.

The diagnostic breakdown of the patients was: schizophrenia ( $\mathrm{n}=121,56.8 \%)$, schizophreniform disorder ( $\mathrm{n}=52,24.4 \%)$, schizoaffective disorder $(n=5,2.3 \%)$, brief reactive psychosis 
( $\mathrm{n}=18,8.5 \%)$, psychosis not otherwise specified $(\mathrm{n}=15,7.0 \%)$, delusional disorder $(\mathrm{n}=2,0.9 \%)$.

Patients and controls were in Hardy-Weinberg equilibrium for the polymorphism studied. Rs821616 genotypic and allelic frequencies were as follow for patients and controls. Patients: $\mathrm{AA}=6.6 \% ; \mathrm{AT}=42.7 \% ; \mathrm{TT}=50.7 \%$ and $\mathrm{A}=0.28 ; \mathrm{T}=0.72$. Controls: $\mathrm{AA}=8.6 \% ; \mathrm{AT}=37 \% ; \mathrm{TT}=54.4 \%$ and $\mathrm{A}=0.27 ; \mathrm{T}=0.73$.

Gender distribution did not significantly differ between patients and controls $\left(\chi^{2}=0.21 ; \mathrm{p}=0.35\right)$. Moreover, gender distribution both in patients and controls was similar in each of the genotype groups (Patients: $\chi^{2}=3.52 ; \mathrm{p}=0.17$; Controls: $\chi^{2}=$ 4.13; $\mathrm{p}=0.13$ respectively).

Allelic and genotypic distributions were not significantly different in patients and controls (Allelic: $\chi^{2}=0.09 ; \mathrm{p}=0.76$; Genotypic: $\chi^{2}=2.04 ; \mathrm{p}=0.36$ ). In the group of patients with psychosis, the statistical analyses failed to show any significant association between Ser704Cys genotypes and age of onset or DUP (Table 1).

When the three commonly used dimensions of psychopathology (positive, negative and disorganised) were analysed, a significant association was found between Ser704Cys genotype and the positive dimension (Table 2); those patients homozygous for the Ser allele showed a higher severity of the positive dimension than Cys allele carriers $(\mathrm{F}=6.85 ; \mathrm{p}=0.009)$ (Figure 1). In a further analysis we explored each of the symptoms included in the SAPS-SANS positive dimension, finding a significant association between Ser704Cys genotype and the item hallucinations $(\mathrm{F}=5.75 ; \mathrm{p}=0.017)$ following the same direction as the previous result; patients with a Ser/Ser genotype showed a mean greater score than Cys carriers (Figure 2).

Table 1. Socio-demographic characteristics of the sample

\begin{tabular}{|c|c|c|c|c|c|c|c|c|c|c|c|c|}
\hline \multirow[b]{3}{*}{ Age } & \multicolumn{2}{|c|}{ Ser-Ser $(N=14)$} & \multicolumn{2}{|c|}{ Ser-Cys $(\mathrm{N}=91)$} & \multicolumn{2}{|c|}{ Cys-Cys $(\mathrm{N}=108)$} & \multirow{2}{*}{\multicolumn{2}{|c|}{ Statistics* }} & \multicolumn{2}{|c|}{ Cys/- (N=199) } & \multirow{2}{*}{\multicolumn{2}{|c|}{ Statistics $^{\dagger}$}} \\
\hline & Mean & $\mathrm{SD}$ & Mean & $\mathrm{SD}$ & Mean & SD & & & Mean & $\mathrm{SD}$ & & \\
\hline & 29.91 & 7.21 & 28.65 & 8.59 & 28.50 & 8.48 & $\mathrm{~F}=0.17$ & $\mathrm{p}=0.84$ & 28.57 & 8.51 & $\mathrm{~F}=0.33$ & $\mathrm{p}=0.56$ \\
\hline Age of onset & 28.19 & 5.03 & 27.27 & 7.95 & 27.33 & 7.99 & $\mathrm{~F}=0.08$ & $\mathrm{p}=0.92$ & 27.3 & 7.95 & $\mathrm{~F}=0.16$ & $\mathrm{p}=0.69$ \\
\hline \multirow[t]{2}{*}{ DUP (months) } & 3.91 & 4.72 & 16.53 & 32.97 & 14.02 & 27.69 & $\mathrm{~F}=1.08$ & $\mathrm{p}=0.34$ & 15.17 & 30.16 & $\mathrm{~F}=1.80$ & $\mathrm{p}=0.18$ \\
\hline & $\mathrm{N}$ & $\%$ & $\mathrm{~N}$ & $\%$ & $\mathrm{~N}$ & $\%$ & & & $\mathrm{~N}$ & $\%$ & & \\
\hline Gender (male) & 11 & 78.6 & 48 & 52.7 & 64 & 59.3 & $\chi^{2}=3.52$ & $\mathrm{p}=0.17$ & 112 & 56.3 & $\chi^{2}=2.66$ & $\mathrm{p}=0.08$ \\
\hline \multicolumn{13}{|c|}{ Diagnostic (6 months-SCID) } \\
\hline Schizophrenia & 8 & 57.1 & 43 & 47.3 & 70 & 64.8 & & & 113 & 56.8 & & \\
\hline Schizophreniform Ds & 6 & 42.9 & 26 & 28.6 & 20 & 18.5 & & & 46 & 23.1 & & \\
\hline Schizoaffective Ds & - & - & 1 & 1.1 & 4 & 3.7 & & & 5 & 2.5 & & \\
\hline Others & - & - & 21 & 22.1 & 14 & 13.0 & & & 35 & 17.5 & & \\
\hline
\end{tabular}

Statistical significance p $<0.05 .{ }^{*}$ statistical analysis (chi-square; Anova) for difference between genotype groups, ${ }^{\dagger}$ statistical analysis (chi-square, Anova) for difference between genotype groups (Ser/Ser vs. Cys carriers). DUP: Duration of Untreated Psychosis, SAPS: Scale for the assessment of positive symptoms, SANS: Scale for the assessment of negative symptoms, SCID: Structured Clinical Interview for DSM-IV

Table 2. Baseline clinical severity

\begin{tabular}{|c|c|c|c|c|c|c|c|c|c|c|c|c|}
\hline & \multicolumn{2}{|c|}{ Ser-Ser $(N=14)$} & \multicolumn{2}{|c|}{ Ser-Cys $(\mathrm{N}=91)$} & \multicolumn{2}{|c|}{ Cys-Cys (N=108) } & \multicolumn{2}{|c|}{ Statistics* } & \multicolumn{2}{|c|}{ Cys/- $(\mathrm{N}=199)$} & \multicolumn{2}{|c|}{ Statistics $^{\dagger}$} \\
\hline & Mean & SD & Mean & SD & Mean & SD & $\mathrm{F}$ & $\mathrm{p}$ & Mean & $\mathrm{SD}$ & $\mathrm{F}$ & $\mathrm{p}$ \\
\hline SAPS & 13.43 & 3.05 & 12.79 & 4.50 & 13.27 & 4.57 & 0.33 & 0.72 & 13.05 & 4.53 & 0.09 & 0.76 \\
\hline SANS & 5.43 & 5.59 & 7.02 & 5.81 & 7.23 & 6.22 & 0.56 & 0.57 & 7.14 & 6.02 & 1.06 & 0.30 \\
\hline \multicolumn{13}{|l|}{ Symptom Dimensions } \\
\hline Positive Symptom & 8.86 & 1.83 & 6.86 & 2.34 & 7.42 & 2.38 & 4.88 & 0.009 & 7.16 & 2.37 & 6.85 & 0.009 \\
\hline Negative Symptom & 3.57 & 3.99 & 5.30 & 5.57 & 5.70 & 5.85 & 0.91 & 0.40 & 5.52 & 5.71 & 1.57 & 0.21 \\
\hline Disorganized Symptom & 4.57 & 3.34 & 5.93 & 3.38 & 5.85 & 3.72 & 0.89 & 0.41 & 5.89 & 3.60 & 1.76 & 0.18 \\
\hline \multicolumn{13}{|l|}{$\begin{array}{l}\text { Positive symptom } \\
\text { dimension's Items }\end{array}$} \\
\hline SAPS Item Hallucinations & 3.86 & 1.83 & 2.16 & 2.23 & 2.53 & 2.32 & 3.52 & 0.031 & 2.36 & 2.28 & 5.75 & 0.017 \\
\hline SAPS Item Delusions & 5.00 & 0.00 & 4.69 & 0.88 & 4.89 & 0.34 & 3.12 & 0.046 & 4.80 & 0.65 & 1.33 & 0.25 \\
\hline
\end{tabular}

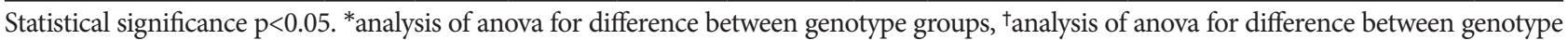
groups (Ser/Ser vs. Cys carriers). SAPS: Scale for the assessment of positive symptoms, SANS: Scale for the assessment of negative symptoms 


\section{DISCUSSION}

Our study detected a significant association between Ser704Cys genotype and severity of positive psychotic symptoms in a well-defined Spanish Caucasian population, measured by the total score in the SANS-SAPS Positive Symptoms dimension, and severity of the Hallucinations, at the onset of the illness. Thus, according to the results, a patient presenting a first episode of psychosis and being homozygous for the Ser allele will present more likely a worse clinical onset of the illness, with more severe positive symptoms and particularly halluci-

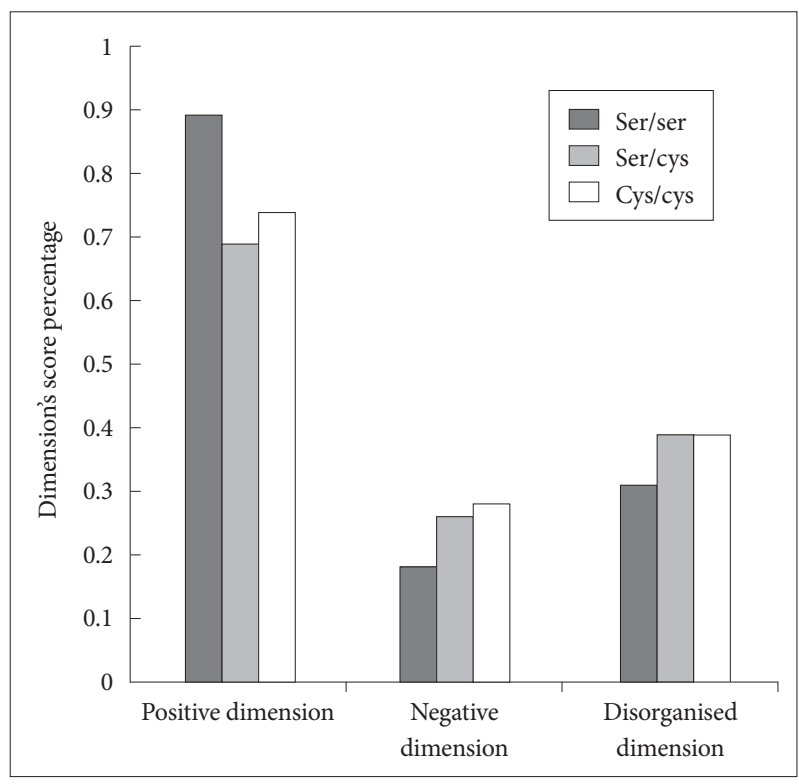

Figure 1. Symptom dimensions and Ser704Cys genotypes. Different range of scores for each dimension: Positive dimension: 0-10 points; Negative dimension: 0-20 points; Disorganised dimension: $0-15$ points.

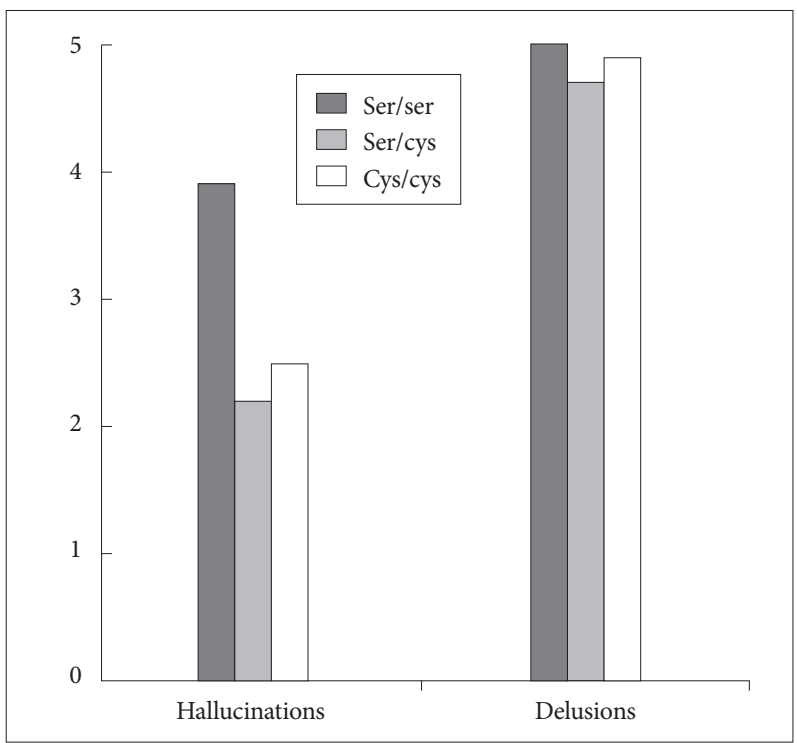

Figure 2. Positive symptom dimension and Ser704Cys genotypes. nations.

This finding is consistent with previous reports of an association between carrying the Cys allele and presenting lower delusional rating in psychotic patients, ${ }^{25}$ and lower rates in the schizoidia scale in healthy subjects. ${ }^{23}$

Other studies linked as well clinical presentation to different DISC1 polymorphisms; thus Hennah et al. ${ }^{11}$ described that a certain DISC1 haplotype (HEP3) displayed association to certain component-traits of Schizophrenia. And similarly another study found an association between the phe allele in leu607phe SNP and severity of hallucinations in a sample of Caucasian patients with a diagnosis of schizophrenia. ${ }^{24}$

Moreover, a recent study acknowledged the possibility that the severity of the psychosis could be the mediating factor in the observed association between a DISC1 rs3738401 variant and ultra-resistance to antipsychotic treatment. ${ }^{31}$

Although DISC1 gene has been postulated as one of the main candidate genes for Schizophrenia, to date there is no clear evidence supporting the Ser704Cys DISC1 SNP as a risk factor for psychosis. While Callicot and colleagues found the Ser allele over-transmitted to psychotic patients in a large family-based sample, ${ }^{7}$ a recent study found no association between this polymorphism and the risk of psychosis. ${ }^{25}$ In line with these results, our study showed no significant association between Ser704Cys polymorphism and risk of psychosis in the northern Spanish Caucasian population studied.

In addition, when studying the effect of this DISC1 genotype on the onset of the illness our study found no association between Ser704Cys polymorphism and age of onset or DUP. This last result is in agreement with a previous study in a sample of schizophrenic Japanese patients. ${ }^{42}$

The biological function of DISC1 is not completely understood, and yet still there is no clear knowledge on how variations in DISC1 gene could modify the clinical presentation of the illness. However, it is today established that DISC1 gene encodes for a scaffold protein that interacts with multiple proteins (DISC1 Interactome) involved in neurodevelopment and neuro-signalling processes. ${ }^{32-35}$

DISC1 protein is expressed in neurons in the brain, predominantly in the hippocampus and cerebral cortex..$^{36}$ DISC1 expression has been shown to be lower in patients with Schizophrenia. ${ }^{37}$ And moreover, those schizophrenic patients Ser homozygous for Ser704Cys DISC1 polymorphism showed a lower expression of some of these partner proteins in these

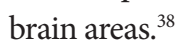

Moreover, Ser/Ser genotype has been associated to a decrease in hippocampal grey matter and to abnormal hippocampal activity during cognitive tasks. ${ }^{7}$ And, in healthy subjects Ser/Ser genotype showed greater activation of the hippocampus $^{15}$ and pre-frontal cortex ${ }^{16}$ during cognitive tasks, suggest- 
ing that these areas needed greater activation to achieve the same level of cognitive functioning of those Cys carrier subjects.

Interestingly, these two brain areas -prefontal cortex and hippocampus- showing structural and functional changes in relation to variations in DISC1 gene, play a central role in the genesis of psychotic symptoms according to the dopamine theory of Schizophrenia. ${ }^{39,40}$ Therefore a plausible explanation for the involvement of DISC1 in psychosis severity is based on its interaction with the dopamine system, perhaps through neurodevelopmental modifications in these brain areas derived from DISC1 gene variations which could ultimately lead to the functional and structural changes described in these two main brain areas as well as differences in clinical severity.

Indeed, a recent review on DISC1details the multiple findings relating DISC1 variations to dopamine system in knockdown mice and cell studies, ${ }^{41}$ in line with this explanatory hypothesis.

These results have to be taken into account with caution; the study should be replicated in larger samples and other DISC1 polymorphisms should be included in the study forming haplotypes to obtain a bigger representation of the DISC1 gene.

The sample used in this study, formed by a wide range of non-affective psychosis diagnosis might be a caveat in the study as the results obtained might be less specific of a core schizophrenia diagnosis sub-sample. However, this study aimed to identify associations between variations in DISC1 gene and clinical severity of the onset of psychosis in a wide scope, and not in a more restricted sample.

The genotype clustering (Ser homozygous versus Cys carriers) carried out in order to facilitate comparison to previous studies, formed two unbalanced groups, which may have influenced the subsequent statistical analyses, therefore representing a possible caveat. However, due to the exploratory nature of this analysis we have considered relevant to include it.

An additional flaw in our study could be the multiple tests done. After correcting for multiple testing the statistical significance didn't survive. However this might be explained by the sample size and it is likely that in a bigger sample the statistical significance would have survived multiple testing corrections.

In conclusion, this study showed a significant association between DISC1 gene Ser704Cys polymorphism and severity of the positive symptoms, in particular hallucinations, at the onset of a first episode of psychosis. Therefore, DISC1 gene variations may modulate the severity of the psychosis at the onset of the illness.

\section{Acknowledgments}

The present study was performed at the Hospital Marqués de Valdecilla, University of Cantabria, Santander, Spain, under the following Grant support: SENY Fundacio Research Grant 2005, Instituto de Salud Carlos III, FIS 00/3095, 03/1009, and PI06/0507, and Fundación Marqués de Valdecilla A/02/07 and API 07/11.

We thank the Spanish Centro Nacional de Genotipado (CEGEN) for carrying out the molecular genetic analysis.

\section{REFERENCES}

1. St Clair D, Blackwood D, Muir W, Carothers A, Walker M, Spowart G, et al. Association within a family of a balanced autosomal translocation with major mental illness. Lancet 1990;336:13-16.

2. Chen QY, Chen Q, Feng GY, Lindpaintner Kl, Wang LJ, Chen ZX, et al. Case-control association study of Disrupted-in-Schizophrenia-1 (DISC1) gene and schizophrenia in the Chinese population. J Psychiatr Res 2007;41:428-434.

3. Hashimoto R, Numakawa T, Ohnishi T, Kumamaru E, Yagasaki Y, Ishimoto T, et al. Impact of the DISC1 Ser704Cys polymorphism on risk for major depression, brain morphology and ERK signalling. Hum Mol Genet 2006;15:3024-3033.

4. Liu YL, Fann CS, Liu CM, Chen WJ, Wu JY, Hung SI, et al. A single nucleotide polymorphism fine mapping study of chromosome 1q42.1 reveals the vulnerability genes for schizophrenia, GNPAT and DISC1: Association with impairment of sustained attention. Biol Psychiatry 2006;60:554-562.

5. Hennah W, Tuulio-Henriksson A, Paunio T, Ekelund J, Varilo T, Partonen T, et al. A haplotype within the DISC1 gene is associated with visual memory functions in families with a high density of schizophrenia. Mol Psychiatry 2005;10:1097-1103.

6. Zhang X, Tochigi M, Ohashi J, Maeda K, Kato T, Okazaki Y, et al. Association study of the DISC1/TRAX locus with schizophrenia in a Japanese population. Schizophr Res 2005;79:175-180.

7. Callicott JH, Straub RE, Pezawas L, Egan MF, Mattay VS, Hariri AR, et al. Variation in DISC1 affects hippocampal structure and function and increases risk for schizophrenia. P Natl Acad Sci U S A 2005;102:86278632 .

8. Ekelund J, Hennah W, Hiekkalinna T, Parker A, Meyer J, Lonnqvist J, et al. Replication of 1q42 linkage in Finnish schizophrenia pedigrees. Mol Psychiatry 2004;9:1037-1041.

9. Kockelkorn TT, Arai M, Matsumoto H, Fukuda N, Yamada K, Minabe $\mathrm{Y}$, et al. Association study of polymorphisms in the 5' upstream region of human DISC1 gene with schizophrenia. Neurosci Lett 2004;368:4145.

10. Hodgkinson CA, Goldman D, Jaeger J, Persaud S, Kane JM, Lipsky RH, et al. Disrupted in schizophrenia 1 (DISC1): association with schizophrenia, schizoaffective disorder, and bipolar disorder. Am J Hum Genet 2004;75:862-872.

11. Hennah W, Varilo T, Kestila M, Paunio T, Arajarvi R, Haukka J, et al. Haplotype transmission analysis provides evidence of association for DISC1 to schizophrenia and suggests sex-dependent effects. Hum Mol Genet 2003;12:3151-3159.

12. Ekelund J, Hovatta I, Parker A, Paunio T, Varilo T, Martin R, et al. Chromosome 1 loci in Finnish schizophrenia families. Hum Mol Genet 2001; 10:1611-1617.

13. Hennah W, Porteus D. The DISC1 pathway modulates expression of neurodevelopmental, synaptogenic and sensory perception genes. PLoS ONE 2009;4:e4906.

14. Mackie S, Millar JK, Porteous DJ. Role of DISC1 in neural development and schizophrenia. Curr Opin Neurobiol 2007;17:95-102.

15. Di Giorgio A, Blasi G, Sambataro F, Rampino A, Papazacharias A, Gambi F, et al. Association of the Ser704Cys DISC1 polymorphism with human hippocampal formation gray matter and function during memory encoding. Eur J Neurosci 2008;28:2129-2136. 
16. Prata DP, Mechelli A, Fu CH, Picchioni M, Kane F, Kalidindi S, et al. Effect of disrupted-in-schizophrenia-1 on pre-frontal cortical function. Mol Psychiatry 2008;13:915-917.

17. Palo OM, Antila M, Silander K, Hennah W, Kilpinen H, Soronen P, et al. Association of distinct allelic haplotypes of DISC1 with psychotic and bipolar spectrum disorders and with underlying cognitive impairments. Hum Mol Genet 2007;16:2517-2528.

18. Cannon TD, Hennah W, van Erp TG, Thompson PM, Lonnqvist J, Huttunen M, et al. Association of DISC1/TRAX haplotypes with schizophrenia, reduced prefrontal gray matter, and impaired short- and long-term memory. Arch Gen Psychiatry 2005;62:1205-1213.

19. Burdick KE, Hodgkinson CA, Szeszko PR, Lencz T, Ekholm JM, Kane $\mathrm{JM}$, et al. DISC1 and neurocognitive function in schizophrenia. Neuroreport 2005;16:1399-1402.

20. Thomson PA, Harris SE, Starr JM, Whalley LJ, Porteous DJ, Deary IJ. Association between genotype at an exonic SNP in DISC1 and normal cognitive aging. Neurosci Lett 2005;389:41-45.

21. Gasperoni TL, Ekelund J, Huttunen M, Palmer CG, Tuulio-Henriksson A, Lönnqvist J, et al. Genetic linkage and association between chromosome $1 \mathrm{q}$ and working memory function in schizophrenia. Am J Med Genet B Neuropsychiatr Genet 2003;116:8-16.

22. Mata I, Perez-Iglesias R, Roiz-Santiañez R, Tordesillas-Gutierrez D, Gonzalez-Mandly A, Berja A, et al. Additive effect of NRG1 and DISC1 genes on lateral ventricle enlargement in first episode schizophrenia. Neuroimage 2010;53:1016-1022.

23. Tomppo L, Hennah W, Miettunen J, Järvelin MR, Veijola J, Ripatti S, et al. Association of variants in DISC1 with psychosis-related traits in a large population cohort. Arch Gen Psychiatry 2009;66:134-141.

24. Szeszko PR, Hodgkinson CA, Robinson DG, DeRosse P, Bilder RM, Lencz T, et al. DISC1 is associated with prefrontal cortical gray matter and positive symptoms in schizophrenia. Biol Psychol 2008;79:103-110.

25. DeRosse P, Hodgkinson CA, Lencz T, Burdick KE, Kane JM, Goldman $\mathrm{D}$, et al. Disrupted in schizophrenia 1 genotype and positive symptoms in schizophrenia. Biol Psychiatry 2007;61:1208-1210.

26. Crespo-Facorro B, Pérez-Iglesias R, Ramírez-Bonilla M, Martínez-García O, Llorca J, Vázquez-Barquero JL. A practical clinical trial comparing haloperidol, risperidone, and olanzapine for the acute treatment of first-episode non-affective psychosis. J Clin Psychiatry 2006;67:15111521.

27. Andreasen NC. Scale for the Assessment of Positive Symptoms (SAPS). Iowa City: University of Iowa; 1984.

28. Andreasen NC. Scale for the Assessment of Negative Symptoms
(SANS). Iowa City: University of Iowa; 1983

29. Grube BS, Bilder RM, Goldman RS. Meta-analysis of symptom factors in schizophrenia. Schizophr Res 1998;31:113-120.

30. Flaum M, O'Leary DS, Swayze VW 2nd, Miller DD, Arndt S, Andreasen NC. Symptom dimensions and brain morphology in schizophrenia and related psychotic disorders. J Psychiatr Res 1995;29:261276.

31. Mouaffak F, Kebir O, Chayet M, Tordjman S, Vacheron MN, Millet B, et al. Association of Disrupted in Schizophrenia 1 (DISC1) missense variants with ultra-resistant schizophrenia. Pharmacogenomics J 2011; 11:267-273.

32. Chubb JE, Bradshaw NJ, Soares DC, Porteous DJ, Millar JK. The DISC locus in psychiatric illness. Mol Psychiatry 2008;13:36-64.

33. Camargo LM, Collura V, Rain JC, Mizuguchi K, Hermjakob H, Kerrien $\mathrm{S}$, et al. Disrupted in Schizophrenia 1 Interactome: evidence for the close connectivity of risk genes and a potential synaptic basis for schizophrenia. Mol Psychiatry 2007;12:74-86.

34. Millar JK, Christie S, Porteous DJ. Yeast two-hybrid screens implicate DISC1 in brain development and function. Biochem Biophys Res Commun 2003;311:1019-1025.

35. Sawa A, Snyder SH. Schizophrenia: neural mechanisms for novel therapies. Mol Med 2003;9:3-9.

36. Wang Q, Jaaro-Peled H, Sawa A, Brandon NJ. How has DISC1 enabled drug discovery? Mol Cell Neurosci 2008;37:187-195.

37. Millar JK, Pickard BS, Mackie S, James R, Christie S, Buchanan SR, et al. DISC1 and PDE4B are interacting genetic factors in schizophrenia that regulate cAMP signalling. Science 2005;310:1187-1191.

38. Lipska BK, Peters T, Hyde TH, Halim N, Horowitz C, Mitkus S, et al. Expression of DISC1 binding partners is reduced in schizophrenia and associated with DISC1 SNPs. Hum Mol Genet 2006;15:1245-1258.

39. Howes OD, Kapur S. The dopamine hypothesis of schizophrenia: version III-the final common pathway. Schizophr Bull 2009;35:549-562.

40. Abi-Dargham A. The Dopamine Hypothesis of Schizophrenia. Schizophrenia Research Forum 2005. Available at: http://www.schizophreniaforum.org/for/curr/AbiDargham/default.asp. Accessed March 11, 2013.

41. Soares DC, Carlyle BC, Bradshaw NJ, Porteous DJ. DISC1: Structure, Function, and Therapeutic Potential for Major Mental Illness. ACS Chem Neurosci 2011;2:609-632.

42. Takahashi T, Suzukia M, Tsunoda M, Maeno N, Kawasakia Y, Zhoua SY, et al. The Disrupted-in-Schizophrenia-1 Ser704Cys polymorphism and brain morphology in schizophrenia. Psychiatry Res 2009;172:128135. 